\title{
A FRAMEWORK FOR ARCHITECTURAL HERITAGE HBIM SEMANTIZATION AND DEVELOPMENT
}

\author{
S. Brusaporci ${ }^{1}$, P. Maiezza ${ }^{1, *}$, A. Tata ${ }^{1}$ \\ ${ }^{1}$ Department of Civil, Construction-Architectural and Environmental Engineering, University of L'Aquila, L'Aquila, Italy - \\ stefano.brusaporci@univaq.it, pamela.maiezza@graduate.univaq.it, alessandra.tata@virgilio.it
}

\section{Commission II, WG II/8}

KEY WORDS: HBIM, Architectural Heritage, Semantization, Level of Development

\begin{abstract}
:
Despite the recognized advantages of the use of BIM in the field of architecture and engineering, the extension of this procedure to the architectural heritage is neither immediate nor critical.

The uniqueness and irregularity of historical architecture, on the one hand, and the great quantity of information necessary for the knowledge of architectural heritage, on the other, require appropriate reflections.

The aim of this paper is to define a general framework for the use of BIM procedures for architectural heritage.

The proposed methodology consists of three different Level of Development (LoD), depending on the characteristics of the building and the objectives of the study: a simplified model with a low geometric accuracy and a minimum quantity of information (LoD 200); a model nearer to the reality but, however, with a high deviation between virtual and real model (LoD 300); a detailed BIM model that reproduce as much as possible the geometric irregularities of the building and is enriched by the maximum quantity of information available (LoD 400).
\end{abstract}

\section{INTRODUCTION}

Building Information Modelling, through an objected-oriented semantic modelling enriched by heterogeneous information, allows

the integration of all aspects of the building process into a single platform.

The working method that is developed, based on an integrated and interactive database, offers advantages and potentials of great interest for the architectural assets documentation.

However, the extension of the BIM process to historic buildings, which led to the creation of the Historical or Heritage BIM, is still an open question today.

The BIM approach, in fact, designed for the project of the new buildings, is hardly combined with the specific needs of the architectural heritage documentation.

There are two main problems:

- the uniqueness of the historical buildings, due to the craftsmanship of its realization, the processes of modification and transformation occurred over time, the phenomena of degradation and deformation;

- the great amount of information necessary for a complete and exhaustive knowledge of the architectural assets.

The objective of this paper is the definition of a methodology concerning the application of the BIM process to the architectural heritage: on the basis of the reflections imposed by the specificity and peculiarity of historical buildings, we want to develop a framework that, starting from the survey of the object of study, aims at the realization of BIM models useful for the documentation of historical buildings, and that can constitute the point of departure for the restoration project, maintenance and management of the architectural asset (Fig.1).

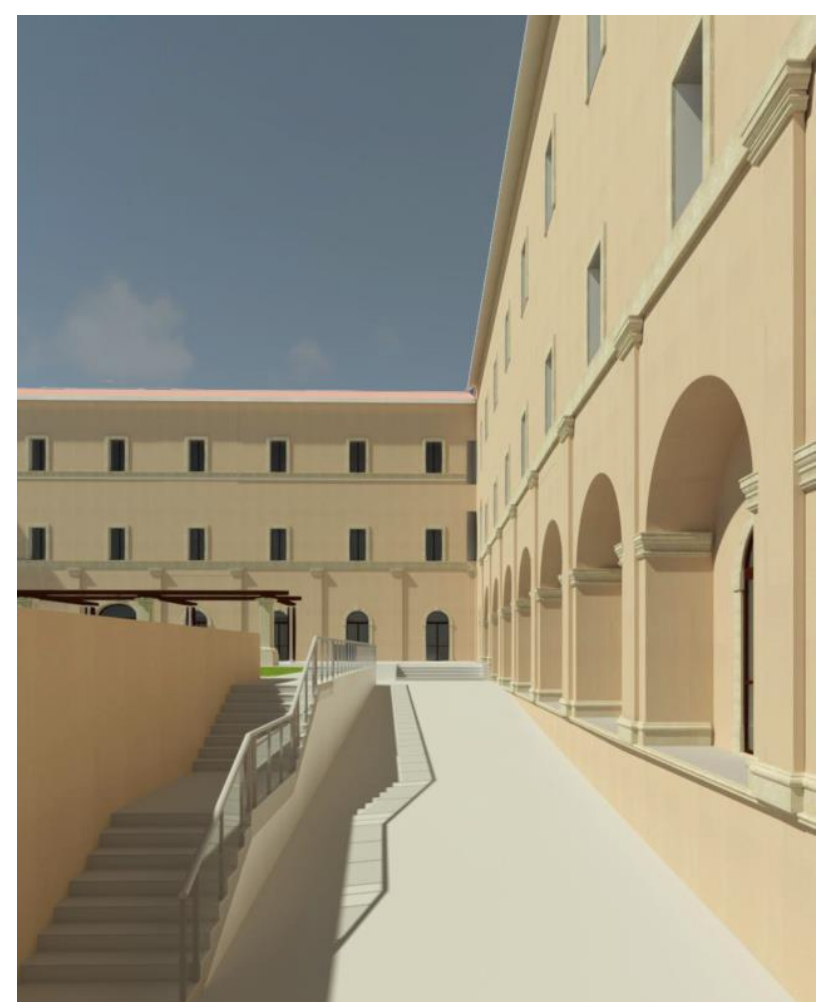

Figure 1. BIM model of Camponeschi palace, L'Aquila (16th century): rendered view of the courtyard.

\footnotetext{
* Corresponding author
} 


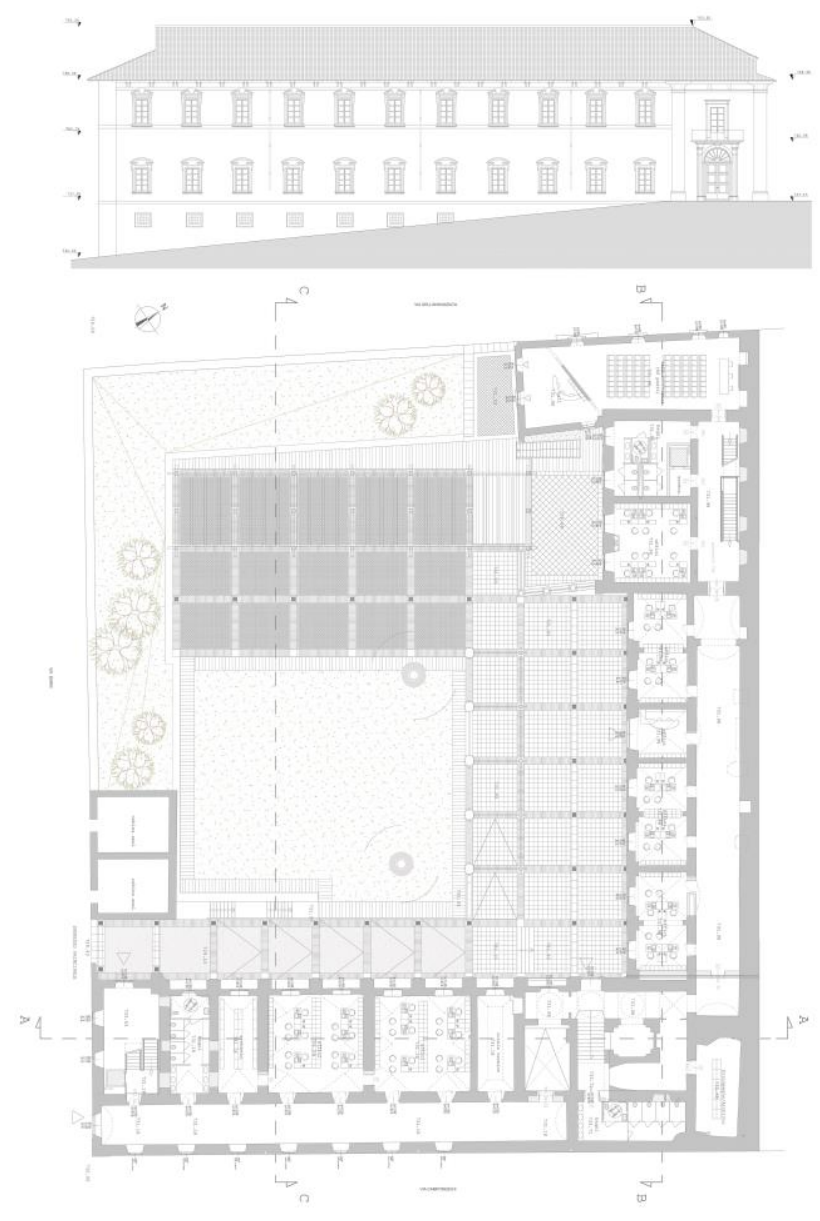

Figure 2. Survey of Camponeschi palace: first level plan and main elevation.

\section{BACKGROUND}

The term HBIM (Historic Building Information Modelling) is born within the Dublin Institute of Technology (Murphy, M. et al., 2009; Murphy, M. et al., 2013).

HBIM is intended as a multidisciplinary system consisting in the construction of smart objects (parameterized on the basis of architectural rules and treatises) on the data deriving from the building survey.

These objects can be used in semi-automatic façade generation procedures, which combine elements from the library on the base of architectural proportions and rules. The façades thus created, as well as the individual elements, can then be modified through a graphic editing, to fit the survey data (Dore and Murphy, 2015).

Since the subject-matter of the HBIM process is the historical building in its current configuration, the survey represents the initial moment of the methodology (Fig. 2).

Current technologies of data massive acquisition (3-D laser scanning and digital photogrammetry) allow to collect accurate survey data of the geometric complexity of the historical building, which must then be translated into BIM digital models.

The realization of the BIM model of architectural assets, because of their uniqueness and geometric complexity, to date, is an open question and an interesting research topic.
Establishing an appropriate level of detail (LoD) for a Historical-BIM is not simple because the BIM LoD for new buildings have to be reconciled with that used in the documentation process (survey data) (Fai, Rafeiro, 2014).

The importance of the modelling theme within the application of BIM to historical architectures is demonstrated by the numerous studies in this regard, which have highlighted different issues: the definition of a pipeline aimed at the translation of collected high definition survey data into smart objects, through the help of a free Autodesk Revit plug-in, codenamed GreenSpider (Garagnani, 2013); the modelling of complex and irregular shapes through NURBS, which, then, thanks to the interoperability with other software, are imported and parameterized in the BIM environment (Oreni et al., 2014); the analysis of the deviation between the ideal model, constructed starting from the treatises (Apollonio et al., 2017) or through ideal generatrixes (Quattrini et al., 2016), with the data deriving from the survey; the creation of ad-hoc libraries of parametric objects for historic buildings (Lo Turco et al., 2017). Alongside the architectural components morphology theme, there is that of information, which is fundamental in the BIM process (Brusaporci and Maiezza, 2016).

In this regard, we recall the research on the integration of the model with an ontology-based system (Simeone et al., 2014), and on the organization of the BIM model database (Inzerillo et al., 2016).

Finally, we mention the studies conducted by Zhang Y. et al. (2016) about a framework on BIM technology for Chinese wooden architectural heritage, and the guidance drawn up by the Historic England organization (2017), addressed the issues surrounding the production and use of BIM for historic buildings.

\section{FRAMEWORK: FROM THE SURVEY TO THE HBIM FOR DOCUMENTATION}

The use of BIM for historical buildings modelling remains problematic and still difficult (Logothetis et al., 2015).

The different methodological approach to the architectural heritage - based on a deep knowledge of the building - makes appropriate reflections necessary.

First of all, the application of a methodology based on standardization to buildings characterized by uniqueness and irregularity generates problems for their modelling.

Reducing the architectural elements of the building to typified objects leads to setting aside the peculiarities of the historical object, in favour of a less time-consuming workflow.

On the contrary, a greater correspondence of the model to the surveyed building leads to a reduction in the benefits of parametric modelling which, on the other hand, results to be greater for elements characterized by lower LoD.

Added to this is the question of information, characterised by two different aspects: on the one hand, there is the need to manage a large amount of data not always supported by current BIM platforms; on the other hand, there is the question of the availability or otherwise of information concerning the various themes (constructive technology, historical phases, etc.) and their interpretation.

However, despite the problems inherent in extending the BIM approach to built heritage, it represents an opportunity both for heritage documentation and for conservation management (Oreni et al., 2013).

Starting from these reflections, in this paper we proposed a general framework aimed at the realization of BIM models of historical buildings, including both the geometrical and the information aspects. 
In order to overcome the problems posed by the BIM for historical buildings, the framework includes different solutions, varying according to the purpose of modelling and the characteristics of the object of study (Fig.3).

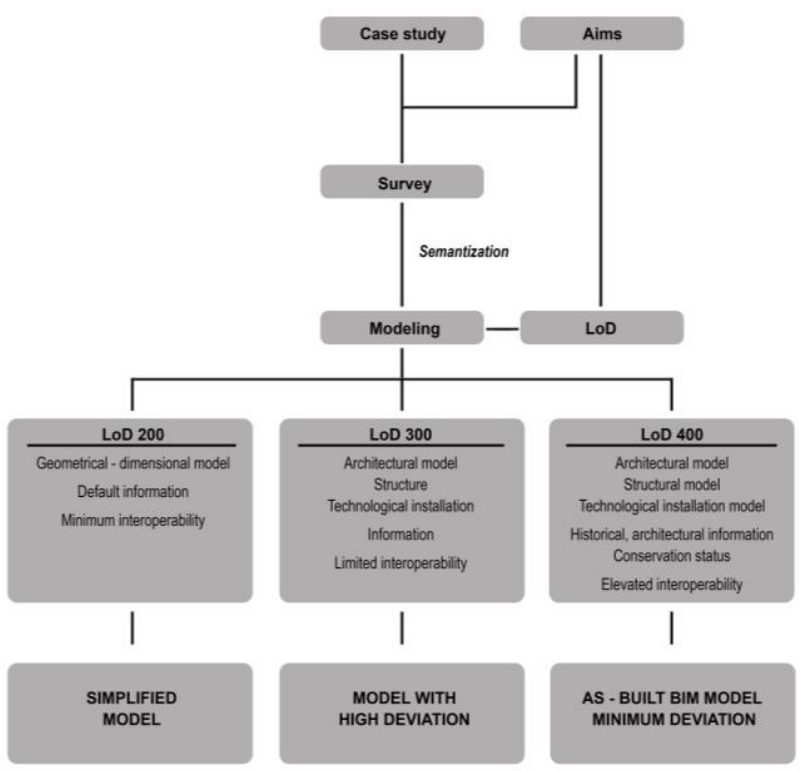

Figure 3. Framework of the BIM process for the architectural heritage and its development.

\subsection{The framework}

Based on the characteristics of the object of study and the aims, the building survey is made, from which, through the semantization of the components, the modelling process can start.

The characteristics of the HBIM models descend from the features of the architectural asset (for example roman building, renaissance palace, baroque church, etc.), the aims of the modelling (geometrical-dimensional survey, survey for the restoration, etc.) and the Level of Development (LoD) desired.

Therefore, the framework includes three main types of model, each characterised by a different Level of Development (based on the definitions by the American Institute of Architects (AIA) for the project of new buildings but here re-used for the existing) and a specific modelling methodology.

The three different types are:

- LoD 200, a simplified model of the building with a low geometric accuracy and a minimum quantity of information.

- LoD 300, in which the amount of information is greater, i.e., through not only the use of family parameters but also the creation of new ones; the modelling is done creating parameterized and simplified families, by which we obtain a model nearer to the reality but, however, with a high deviation between virtual and real model.

- LoD 400, which reproduce as much as possible the geometric irregularities of the building and is enriched by the maximum quantity of information (through an extended database in which also all the information from the historical-critical analysis are embedded).

The detailed modelling is obtained by using families created ad hoc (based on Boolean operations) or, in the case of particularly complex and irregular geometries, integrating the model with NURBS (Non Uniform Rational Basis-Splines) imported and parameterized.

Thus, we get the AS-BUILT BIM: a detailed model as close as possible to historical building, with a minimum deviation and characterised by a high definition from both an architectural and an informative point of view.

As an example, we present the three corresponding types of vault model (Fig. 4):

- A model with LoD 200, with no structural interest; it is possible to model it in-place, realizing the vault as a single element, through extrusion and subtraction operations.

- A model with LoD 300, in which there is also interest in a structural model. The only use of a stratified model inplace is not enough because it doesn't have any structural value; it is therefore necessary to superimpose a structural floor, made as a single layer.

- A model with LoD 400, detailed from both a structural and architectural point of view and inclusive of all constitutive layers.

In order to have a structural BIM object, it is necessary to superimpose a model in-place, which fulfils the architectural and informative task (a detailed model, complete with all the information available concerning each single layer of the vault), on a structural floor, created ad hoc, that coincides with the 3 -D architectural element (i.e. a floor of the maximum height of the vault, emptied into the underlying part).

The complete knowledge of the vault stratigraphy, which allowed the achievement of a similar LoD, was possible thanks to the restoration of the building, which led to the consolidation of the vault with glass fibers (Fig.4).

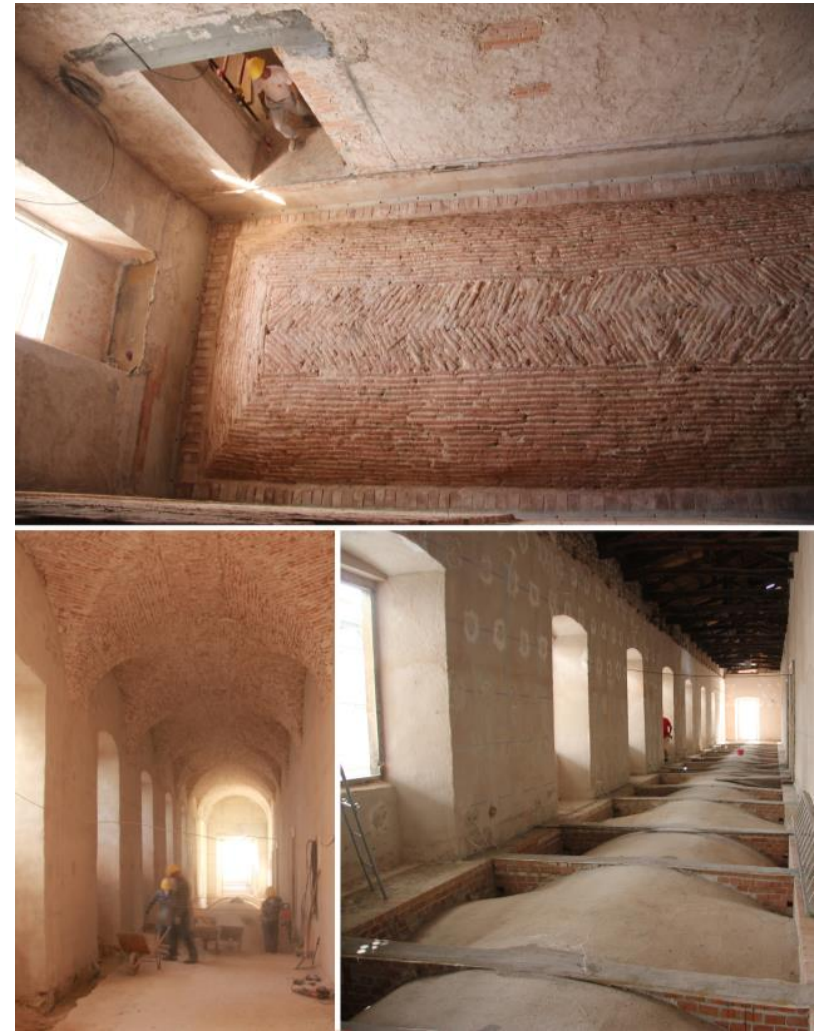

Figure 4. Photo of the restoration of Camponeschi palace realized after the 2009 earthquake: consolidation of the brick vaults with glass fibers. 

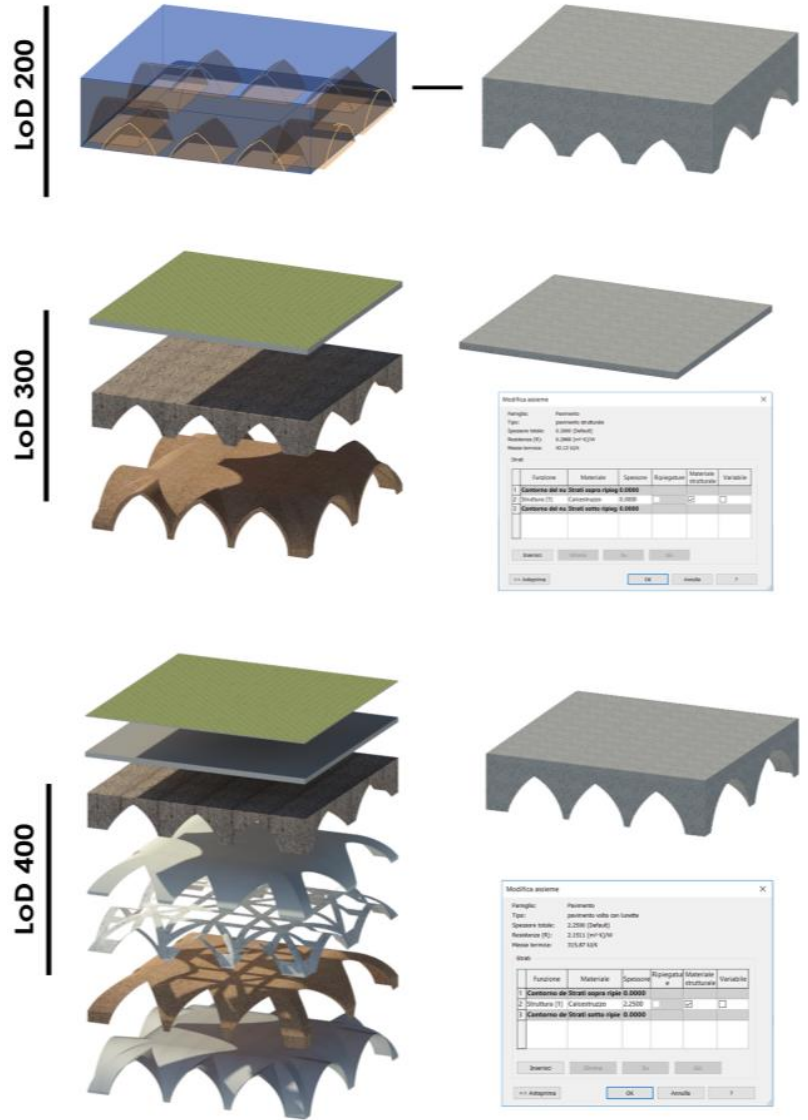

Figure 5. Modelling of a Cavetto vault with lunettes, with different Levels of Development: the LoD 200 vault (on the left the construction of a simplified model in-place of the vault, on the right the final result); the $300 \mathrm{LoD}$ vault (the model in-place with a simplified stratigraphy of the vault and a simplified shape of a structural floor to be superimposed); the LoD 400 vault (the model in-place with a detailed stratigraphy of the vault and a detailed structural floor).

\subsection{Transparency and model reliability}

With the spread of digital tools and applications, which have become increasingly accessible by everyone, the concept of transparency for modelling and visualization of architectural heritage plays a central role.

For transparency, essential references are The London Charter (2009) and the Principles of Seville (2012).

The London Charter defines "intellectual transparency" as "the provision of information, presented in any medium or format, to allow users to understand the nature and scope of "knowledge claim" made by a computer-based visualisation outcome" (p.12). According to Principles of Seville, "All computer-based visualisation must be essentially transparent, i.e. testable by other researchers or professionals, since the validity, and therefore the scope, of the conclusions produced by such visualisation will depend largely on the ability of others to confirm or refute the results obtained" (p. 8).

The principle of transparency has been developed in the field of archaeology, which immediately looked with interest at the potential offered by the digital reconstruction of artefacts no longer existing.
Transparency refers to the declaration of sources on which virtual reconstruction is based (survey data, documentary reference, etc.) and, therefore, of the reliability degree of the model itself.

It makes digital visualization testable by other professionals, who can thus confirm or deny the results obtained by other researchers.

The modeling of historical buildings for their documentation imposes specific reflections on the adherence of the model to the real object.

For transparency, an essential role is played by the paradata. In accordance with the The London Charter, paradata are "Information about human processes of understanding and interpretation of data objects. Examples of paradata include descriptions stored within a structured dataset of how evidence was used to interpret an artefact, or a comment on methodological premises within a research publication. It is closely related, but somewhat different in emphasis, to "contextual metadata", which tend to communicate interpretations of an artefact or collection, rather than the process through which one or more artefacts were processed or interpreted" (p.13).

The paradata constitute a kind of metadata useful for the philological reconstruction of the realization of the model. Bentkowska-Kafel, Denard, Baker (2012) highlight how "[...] the digital techniques - it is argued here - are only useful and valid if interpretative frameworks and processes are published" Hence the importance of paradata: "[...] the term borrowed from other disciplines that rely on recording information processes. Paradata document the process of interpretation so that the aims, contexts and reliability of visualization methods and their outcomes can be properly understood" (p.1).

As regards architectural heritage, a reflection on the theme of the trapsarence and model reliability is in Brusaporci (2017): "Considering digital heritage transparency, we could say that there are two main topics: Transparency of the model toward the existing physical reality; Transparency of virtual reconstructions, in particular when we don't have an immediate physical reference. Focusing on digital heritage, we could indicate two kinds of paradata:

1. Intrinsic Paradata: To declare choices about instruments and tools, applications, and their use, computing workflow, surveying pipeline and tools, 3D modeling and rendering, database modeling, etc. that is the architecture of the model and of the process. This paradata is similar to the traditional one in surveying process.

2. Extrinsic Paradata: About the relation of the computer visualization with: Heritage's nature and characteristics, Archival documents, Scholar's experiences, skills, and decisions. The paradata has to describe the critical interpretation of sources by the scholar and, therefore, presets a degree of reliability.

The model is affected by: Kind of source; Source completeness; Source reliability; Level of interpretation of sources. Thus the model has a degree of Objectivity/Believability. The scholar(s) has to define critical degrees of reliability of the 3D model for the following items: Geometry; Location/Position; Date/Age; Colour/Texture; Material/Constructive system; Context (urban rural - natural) /Landscape.

Obviously intrinsic and extrinsic paradata are related, and both of them derives from scholar's critical choices." (pp.81-82).

Since BIM is an information management system, it can easily provide paradigms relating to reliability.

In the case of BIM, the reliability of the model - essential metadata to define the informative framework for the construction of the model (Bianchini et al., 2017) - must 


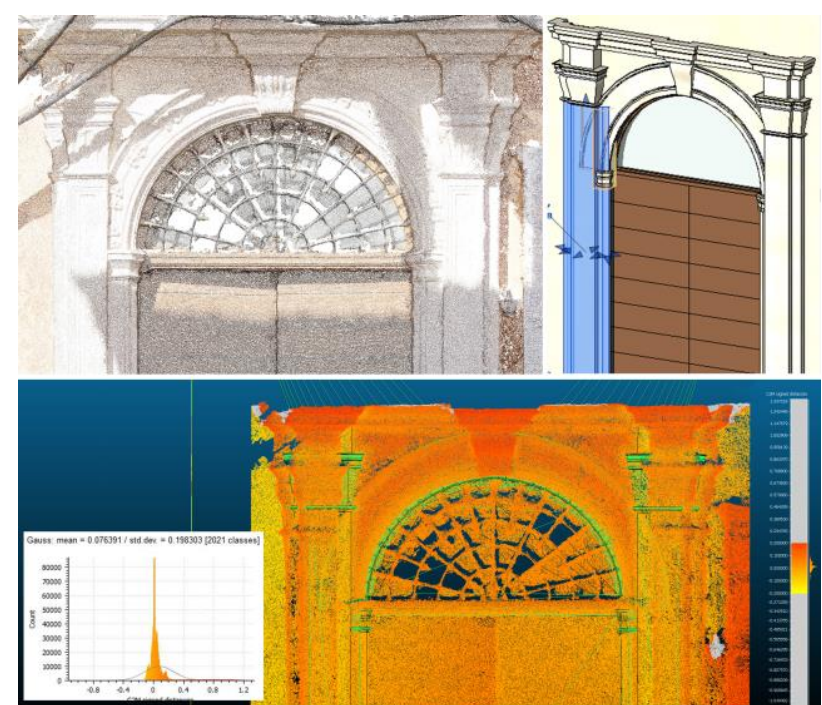

Figure 6. Geometric accuracy of the BIM model: deviation between the model of the main portal of Camponeschi palace and the point cloud (measurement performed within the

CloudCompare software).

concern both the geometry and the information content connected to it (construction technology, historical phases, etc.).

Modelling in the BIM environment is based on the use of semantically recognized objects, which are enriched by information of various kinds (materials, technical features, costs, temporal phases, etc.)

The description of the architectural element also from the constructive point of view, as well as geometric, marks an important distinction from the use of BIM in new buildings.

In this last case, in fact, there is a progressive advancement of the project development which corresponds to a gradual increase in the definition of building components.

Step by step, the LoD are growing up to achieve a complete definition of the architectural and construction aspects of the building.

In HBIM, however, the object of study is the constructed building for which, even at the end of the analysis path, it is not said that a complete and uniform knowledge of the artefact is reached. Depending on the availability of information, in fact, parts of the building can be better defined and parts more unknown, with consequent non-homogeneous LoD.

In order to know the construction technology of a historic building, the references are archival documentation, diagnostic tests, building observation, comparison with buildings similar in age and characteristics, etc.

However, a complete knowledge of the components of a historic building, characterized by total reliability, can only be reached in the phase of construction site when, as in the case of the vaults consolidation, the element is uncovered.

The close connection between the representation of the building construction technology and the sources from which it is derived, leads to the problem of transparency and the consequent need to declare the level of reliability of the various modeled elements.

The reliability of the model in terms of geometric accuracy, on the other hand, is evaluated on the basis of the deviation between the model and the survey data (Fig.6).

In the case of unacceptable deviation values (in accordance with the desired LoD), the architectural elements are corrected by abandoning the ideal geometry and using the characteristics extracted from the survey.
For particularly irregular shapes, for which the Boolean operations are not sufficient, it may be appropriate to use NURBS (Non Uniform Rational B-Splines) which, then, taking advantage of interoperability between different formats, are imported in BIM environment and enriched by information.

Despite the possibility to parameterize these objects, it should be noted that the specificity of their shape, strictly tied to the characteristics of the historical object in question, hardly allows its reuse.

Consequently, the parameterization of these elements is limited to the attributes necessary for the case study.

\section{CONCLUSIONS}

The proposed study analyses advantages, limitations and problems in the use of BIM procedures for architectural heritage.

The peculiarities of architectural assets mean that the extension of the BIM methodology to them is not automatic, but it needs specific reflections aimed at declining this process to meet the historic buildings requirements.

Based on these considerations, the paper proposes a framework aimed at developing a BIM model of the architectural asset.

Taking into account the characteristics of the object of study and the goals pursued, the survey of the historical building is realized, from whose definition the accuracy of the model depends.

The proposed methodology provides for three different Levels of Development.

As the Lod grows, there is a progressive increase in information and geometric content: from a simplified model (LoD 200), a detailed BIM model is obtained from both an architectural and structural point of view (LoD 400), passing through an intermediate level between the two (LoD 300).

The difficulty in reconciling the complexity of the components of historical architecture (for example a vault with its articulated stratigraphy), with BIM objects also characterized by structural value, has been overcome by superimposing two different types of models: a model in-place that, according to LoD, is as close as possible to the real object from an architectural point of view (both for its single parts and for its geometric complexity), and a model with a structural value, which is superimposed on the first.

The geometric definition of the model is evaluated by measuring its deviation from the point cloud.

If this is not compatible with the desired LoD, the architectural element is re-modelled by abandoning the ideal geometries and, if necessary, using NURBS surfaces imported and parameterized.

A Level of Development of 400 requires a deep knowledge of the architectural object.

If on the one hand a high definition of the survey data is essential, on the other hand an important quantity of information of various kinds (constructive, historical, etc.) is necessary. Therefore, the transparency of the sources, which have substantiated the modelling and the creation of the database, and the consequent level of reliability of the model itself, become fundamental.

A similar model, including all the aspects necessary for documentation, can offer itself as a foundation for the restoration project, maintenance and management of the architectural heritage. ${ }^{1}$

\footnotetext{
${ }^{1}$ Although the contribution was conceived jointly, Stefano Brusaporci is author of paragraphs 1 and 4, Pamela Maiezza of 2 and 3.2; Alessandra Tata of paragraphs 3 and 3.1.
} 


\section{ACKNOWLEDGEMENTS}

The research has received funding from the Italian Government under Cipe resolution n.135 (Dec. 21, 2012), project INnovating City Planning through Information and Communication Technologies (INCIPICT).

\section{REFERENCES}

Apollonio, F. I., Gaiani, M., Sun, Z, 2017. A Reality Integrated BIM for Architectural Heritage Conservation. In: Ippolito, A. Handbook of Research on Emerging Technologies for Architectural and Archaeological Heritage. IGI Global, Hershey, PA, pp. 31-65.

Bentkowska-Kafel, A., Denard, H., \& Baker, D., 2012. Paradata and Transparency in Virtual Heritage. Ashgate Publishing, Farnham.

Bianchini, C., Inglese, C., Ippolito, A., Maiorino, D. and Senatore, L. J., 2017. Building Information Modeling (BIM): Great Misunderstanding or Potential Opportunities for the Design Disciplines?. In: A., Ippolito, M., Cigola, Handbook of Research on Emerging Technologies for Digital Preservation and Information Modeling. IGI Global, Hershey, PA, pp. 67-90.

Brusaporci, S., Maiezza, P., 2016. Re-Loading BIM: Between Spatial and Database Information Modeling for Architectural Heritage Documentation. In: AA.VV. Dibujar, Construir, Sonar. Investigaciones en torno a la expresion grafica aplicada a la edificacion. Tirant Lo Blanch, Valencia, pp. 835-847.

Brusaporci, S., 2017. The importance of being honest. In Ippolito, A., Emerging technologies for architectural and archaeological heritage. IGI Global, Hershey, PA, pp. 66-93.

Dore, C., Murphy, M., 2015. Historic Building Information Modeling (HBIM). In: Brusaporci, S., Handbook of Research on Emerging Digital Tools for Architectural Surveying, Modeling, and Representation. IGI Global, Hershey, PA, pp. 239-279.

Fai, S., Rafeiro, J., 2014. Establishing an appropriate level of detail (LoD) for a building information model (BIM) - West Block, Parliament Hill, Ottawa, Canada. In: ISPRS Annals of the Photogrammetry, Remote Sensing and Spatial Information Sciences, Vol. II-5, pp. 123-130.

Garagnani, S., 2013. Building Information Modeling a real world knowledge. A methodological approach to accurate semantic documentation for the built environment. Digital Heritage International Congress (DigitalHeritage), 2013 1, pp. 489-496.

Historic England, 2017. BIM for Heritage: Developing a Historic Building Information Model. Swindon. Historic England.

Inzerillo, 1., Lo Turco, M., Parrinello, S., Santagati, C., Valenti, G. M., 2016. BIM and architectural heritage: towards an operational methodology for the knowledge and the management of Cultural Heritage. In: DISEGNARE CON vol. 9 n. 16, pp. 16.1-16.9.
Logothetis, S., Delinasiou, A., Stylianidis, E., 2015. Building Information Modelling for cultural heritage: a review. In: ISPRS Annals of the Photogrammetry, Remote Sensing and Spatial Information Sciences, Vol. II-5/W3, pp. 177-183.

Lo Turco, M., Santagati, C., D’Agostino, G., 2017. Populating a library of reusable $\mathrm{H}$-BOMs: assessment of a feasible image based modelling workflow. In: International Archives of the Photogrammetry, Remote Sensing, Vol. XLII-2/W5, pp. 627634.

Murphy, M., McGovern, E., Pavia, S., 2009. Historic building information modelling (HBIM) In: Structural Survey, Vol. 27 Issue: 4, pp.311-327.

Murphy, M., McGovern, E., Pavia, S., 2013. Historic Building Information Modelling - Adding intelligence to laser and image based surveys. In: ISPRS Journal of Photogrammetry and Remote Sensing, Vol. 76, pp. 89-102.

Oreni, D., Brumana, R., Della Torre, St., Banfi, F., Barazzetti, L., Previtali, M., 2014. Survey turned into HBIM: the restoration and the work involved concerning the Basilica di Collemaggio after the earthquake (L'Aquila). In: ISPRS Annals of the Photogrammetry, Remote Sensing and Spatial Information Sciences, Vol. II, 2014, pp. 267-273

Oreni, D., Brumana, R., Georgopoulos, A., Cuca, B., 2013. HBIM for conservation and management of built heritage: towards a library of vaults and wooden bean floors. In: ISPRS Annals of the Photogrammetry, Remote Sensing and Spatial Information Sciences, Vol. II-5/W1, 2013, pp. 215-221.

Principles of Seville, 2012. Retrieved from $\mathrm{http} / / /$ smartheritage.com/seville-principles/seville-principles

Quattrini, R., Clini, P., Nespeca, R., Ruggeri, L., 2016. Measurement and Historical Information Building: Challenges and opportunities in the representation of semantically structured 3D content. In: DISEGNARE CON vol. 9 n. 16, pp. 14.1-14.11.

Simeone, D., Cursi, S., Toldo, I., Carrara, G., 2014. BIM and knowledge management for building heritage. In: Gerber, D. Acadia 2014 Design Agency: Proceedings of the 34th Annual Conference of the Association for Computer Aided Design in Architecture, Roundhouse Publishing Group, Brightonpp, pp. 681-690.

The London Charter, 2009. Retrieved from: http://www.londoncharter.org/

Zhang, Y., Zhu, Z., Li C., Chang, L., 2016. Integration application system of Chinese wooden architecture heritages based on BIM. In: 2016 International Conference on Logistics, Informatics and Service Sciences (LISS).

Revised March 2018 